\title{
Barreiras para a prática de exercício físico em adultos
}

\section{Barriers to physical exercise among adults}

\begin{abstract}
RESUMO
O presente estudo teve como objectivo conhecer as barreiras para a prática de exercício físico numa amostra de adultos. A nossa amostra foi composta por 13 sujeitos entre os 21 e 35 anos, praticantes e não praticantes de exercício físico, e foi recolhida no norte de Portugal. Usamos como método de recolha de dados a entrevista centrada no problema. Através do processo de codificação e categorização, obtivemos 7 constructos que identificámos como barreiras: falta de tempo; desinteresse / aversão pelo exercício físico; incompetência; suporte familiar / pares; estereótipos / preconceitos sexuais; falta ou insuficiência de infra-estruturas / falta de condições; carência de recursos económicos / monetários. Seria interessante que um estudo de natureza quantitativa procurasse confirmar as nossas hipóteses numa amostra de maior proporções e abrangente.
\end{abstract}

Palavras-chave: exercício físico, barreiras, adultos

\begin{abstract}
This study aimed to identify the barriers to the practice of physical exercise in a sample of adults. Our sample was composed of 13 participants between 21 and 35 years old, practitioners and nonpractitioners of physical exercise residing in the north of Portugal. The data collection method was the interview focused on the problem. Applying the coding and categorization processes, we identified seven constructs. They were: lack of time; disinterest by the exercise/aversion; incompetence; family support/couples support; stereotypes/sex prejudices; lack or insufficiency of infrastructure/lack of terms; lack of economic resources/money. It would be interesting that a study of a quantitative nature seek to confirm our assumptions on the adult population.
\end{abstract}

Keywords: physical exercise; barriers, adults 
O cenário português relativamente à prática de exercício físico não é, definitivamente, um dos melhores ao nível da união europeia. Verifica-se que Portugal apresenta uma das maiores taxas no que se refere à ausência de prática de exercício físico ou desporto. Dados do Eurobarometer (2004) revelam que 66\% da população portuguesa afirma não praticar qualquer tipo de exercício físico ou qualquer tipo de desporto. Este é um valor que coloca o país na "cauda da Europa" no que diz respeito a indivíduos sedentários, apesar de $79 \%$ destes considerar que a prática de exercício físico ajuda a melhorar a saúde, quer física, quer mental. Portanto, há uma consciencialização por parte dos portugueses relativamente aos benefícios em se ser mais activo. $\mathrm{O}$ facto de se participar em actividades físicas traz consigo um conjunto de implicações ao nível da saúde, estando o sedentarismo associado a múltiplas doenças (Norton, Burns, Hope, \& Bauer, 2000). Quando questionados acerca da eficácia da prática de desporto no combate à obesidade, $87 \%$ dos respondentes concordaram que é importante para ter bons índices de saúde (Eurobarometer, 2004). No entanto, cerca de $41.1 \%$ dos homens portugueses e $30,8 \%$ das mulheres encontram-se num estado de pré-obesidade, e $11.3 \%$ dos homens e $12.2 \%$ das mulheres portuguesa encontram-se num estado de obesidade tipo I (Carmo, 2001).

Existe um notável contraste entre os países nórdicos da Europa e os países mediterrâneos, incluindo Portugal. Os resultados do Eurobarometer indicam que os países escandinavos são os que apresentam a taxa mais elevada de praticantes de exercício físico. Cerca de $75 \%$ dos Finlandeses e $72 \%$ dos Suecos afirmam praticar exercício físico pelo menos uma vez por semana, enquanto apenas $22 \%$ dos Portugueses afirmam praticar exercício físico com a mesma frequência. O mesmo relatório sugere-nos, também, que a prática de exercício físico está relacionada com o nível de instrução. Dos indivíduos que terminaram os seus estudos até aos 15 anos de idade, apenas $20 \%$ pratica semanalmente exercício físico. Esta percentagem aumenta para $32 \%$ nos indivíduos que acabaram os seus estudos entre os 16 e os 19 anos de idade e alcança os $50 \%$ nos indivíduos que completaram os seus estudos com 20 anos ou mais.

Ainda segundo a mesma fonte, $50 \%$ dos inquiridos portugueses que nunca praticam exercício físico, afirmam que a principal razão pela qual não praticam, é a falta de tempo. No entanto, ao nível da União Europeia, esta percentagem reduz-se para $34 \%$ (o que corresponde a um terço de toda a união), seguido pelo facto de não gostarem de praticar desporto (25\%). Em terceiro lugar encontram-se as condições financeiras (4\%) e por último a ausência de boas infra-estruturas perto do local de residência $(3 \%)$. Os indivíduos entre os 25 e os 39 anos que consideram a falta de tempo como a sua principal barreira para a prática de exercício físico são cidadãos empregados ou com níveis de escolaridade elevados (61\% e $62 \%$, respectivamente). Ao nível de cada país da União, quando comparados, os Cipriotas aparecem em primeiro lugar no que se refere ao facto de não praticarem exercício físico devido à falta de tempo $(66 \%)$, seguidos dos Malteses (56\%) e dos Portugueses (50\%) que contrastam com os Alemães, Austríacos e Finlandeses onde apenas $21 \%$, 21\% e $19 \%$, respectivamente, consideram a falta de tempo uma barreira para a prática de exercício físico (Eurobarometer, 2004). O mesmo relatório em 2018 apresenta a Bulgária com 83\%, Roménia $81 \%$, Grécia $77 \%$, Hungria, 76, Portugal $74 \%$, ... Holanda 43, Dinamarca 37\%, Suécia 33\%, Finlândia $31 \%$.

Portanto, vistos os resultados até agora apresentados, torna-se importante verificar quais são as barreiras que os indivíduos portugueses, uns dos mais inactivos da Europa, encontram e que lhes dificulta ou impede a prática de exercício físico.

Antes de avançarmos com uma revisão de 
literatura mais alargada convém contextualizarmos o conceito "exercício físico" e procurar a sua definição. Frequentemente, no senso comum, os termos actividade física, exercício físico, e até desporto, surgem como sinónimos. No entanto, estes conceitos distinguem-se. Segundo Caspersen, Powell e Christenson (1985) s por actividade física devemos entender qualquer movimento corporal produzido pelos músculos esqueléticos. Apesar de simples, esta definição salienta a complexidade comportamental deste construto, na medida em que abrange um imenso grupo de comportamentos que teoricamente incluem qualquer movimento corporal que termine em dispêndio energético acima do nível basal. Por sua vez, o exercício físico é uma subcategoria da actividade física definida como estruturada, planeada, e repetitiva com o objectivo de manter ou melhorar a aptidão física (Caspersen et al., 1985, p. 128). O desporto é também uma subcategoria da actividade física mas neste caso verifica-se uma diferença na sua definição entre os EUA e a Europa. Enquanto nos EUA o desporto implica necessariamente uma actividade competitiva orientada para a performance e desempenho, na Europa pode envolver actividades de lazer e recreação. Portanto, entendemos a actividade física como um construto de segunda ordem, mais aglutinador e que engloba o exercício físico e o desporto.

Segundo um estudo publicado em Março de 2006 no jornal Medicine \& Science in Sport \& Exercise, jornal oficial do American College of Sports Medicine (ACSM), a principal barreira para a prática de exercício físico, segundo adolescentes do sexo feminino, é a falta de tempo (Kimm, et al., 2006). Este estudo revelou também que as jovens adolescentes têm um conjunto de hábitos sedentários, devidos principalmente a barreiras intrínsecas (falta de interesse, falta de motivação, etc.). Foram analisadas cerca de 2000 adolescentes e mais de metade delas afirmaram ser sedentárias. Este grupo de indivíduos, sedentários ou inactivos, revelou também que se sentia demasiado cansado ou sem interesse em praticar exercício físico e tem medo de se magoar. As adolescentes evidenciaram também que as percepções acerca do seu próprio corpo as impediam de praticar exercício. No entanto, os investigadores obtiveram também outras conclusões interessantes: não se verificaram diferenças no número de horas de trabalho ou tarefas domésticas das participantes, quer sejam activas quer sejam inactivas. Para além disto, as raparigas que se afirmaram muito cansadas para praticar exercício físico têm aproximadamente as mesmas horas de sono do que as que praticam (Kimm et al., 2006). Isto leva-nos a constatar que no grupo de raparigas inactivas a principal barreira não é a falta de tempo, mas sim a dificuldade de "gestão" de tempo e a ausência de motivação para a prática de exercício físico.

Um outro estudo que analisou mulheres africanas com 50 anos, a viver na Carolina do Sul (EUA), indentificou que estas mulheres identificam como principais barreiras para a prática de exercício físico os riscos que correm ao praticá-lo, assim como o facto de já estarem numa idade avançada, e, portanto, "muito velhas" para praticarem (Wilcox, Oberrecht, Bopp, Kammermann \& McElmurray, 2005). Para além destas barreiras, visto que estas mulheres moram em meios rurais, também referiram a falta de transportes, de equipamentos, assim como a ausência de programas de exercício físico adequados para a sua idade (idem).

O estudo de Amesty (2003) refere as características individuais como factores que predispõem os indivíduos para a prática de actividade física, principalmente se conjugados com o contexto onde esta ocorre. A autora refere que as variáveis individuais e comunitárias, tais como o suporte social, a pobreza, o nível de instrução, o processo de aculturação e os sentimentos de segurança, só podem ser compreendidas enquanto barreiras para a prática de exercício, se tivermos em conta o contexto onde as pessoas vivem. Ainda neste estudo verificou-se 
que os indivíduos com um fraco suporte social têm tendência para serem mais inactivos do que aqueles que referem ter boas relações sociais e suporte social, especialmente o suporte familiar e dos amigos. Sectores como estes, família e amigos, são especialmente importantes para uma motivação inicial que permite aos indivíduos aumentar a sua participação em actividade física.

Kolt, Paterson e Cheung (2006) quando estudaram adultos neozelandeses, identificaram como barreiras para a prática de actividade física a ausência de motivação, a influência familiar, assim como o nível de instrução e as expectativas culturais. No entanto, os respondentes também identificaram um conjunto de benefícios derivados da actividade física, desde os sociais, psicológicos, cognitivos e físicos. Tais constatações levou os autores do estudo a sugerir que se houver incentivos por parte das entidades governamentais, médicas e até religiosas, estes indivíduos poderão tornar-se facilmente activos.

Por sua vez, Pereira e Vasconcelos Raposo (1997), numa população adulta residente no interior norte de Portugal identificaram de 5 factores pelos quais as pessoas não aderiam em actividades físicas: Aversão desportiva/ Insatisfação; Estética/ Incompetência; Falta de apoios/ condições; Desinteresse pelo esforço físico; e Falta de tempo.

Um estudo realizado em 2004, um grupo de mulheres adultas e adolescentes, todas inactivas até ao momento de recolha de dados, foi convidado a praticar exercício físico, durante 12 semanas. Metade do grupo praticou exercício físico numa universidade (aeróbica), 3 vezes por semana, enquanto a outra metade do grupo praticou em casa exercícios relacionados com força física, usando os utensílios que dispunha em casa. Este último grupo dispunha de um calendário para programar os seus exercícios e fotografias com vários exercícios possíveis de realizar com os seus utensílios. No final do estudo, a conclusão mais importante a que se chegou foi a que tanto as mulheres que praticaram exercício na universidade, como as mulheres que praticaram exercícios em casa com os seus utensílios, referiram menos barreiras para a prática de exercício físico, do que as que tinham referido inicialmente (Ransdell, Detling, Hildebrand, Lau, Moyer-Miller $\&$ Shultz, 2004). No entanto, estes resultados não se verificaram nas participantes mais jovens. Isto talvez se possa explicar pelo facto das adolescentes terem menos suporte social para a prática de exercício físico, assim como poucos modelos sociais a seguir. Por sua vez, as mulheres podem sentir que têm maior controlo sobre as suas vidas, ao passo que as adolescentes são "controladas" pelos pais, precisando de transporte, dinheiro e permissão (que podem ser barreiras para a prática de exercício físico). Este aspecto merece uma atenção especial por que indivíduos que encontrem muitas barreiras e reconheçam poucos benefícios na prática de exercício físico tendem a ser mais inactivos do que os indivíduos que encontram poucas barreiras e mais benefícios. No entanto, as principais barreiras ainda identificadas pelas mulheres no final do estudo foram o dispêndio de tempo e o esforço físico. Em muitos estudos realizados com mulheres de diferentes escalões sociais, as barreiras frequentemente encontradas foram as expectativas sociais, medo de se magoar, medo da criminalidade, falta de tempo e falta de condições motivadoras (facilitadores). Para além disto, identificaram também como barreira o embaraço que sentiam ao praticar exercício físico (Ransdell et al., 2004). Alves, Cunha e Leirós (2008), referem que estes casos muitas vezes estão associados a indivíduos com elevada ansiedade física social induzindo um estado meta-motivacional télico (orientado, neste caso, para a impressão que se está a transmitir aos outros) durante a prática de exercício físico. Quando neste estado motivacional, aumenta a apreensão e o medo de uma avaliação corporal negativa e consequentemente vai despoletar um desejo de desistência 
e evitamento. Para além disto, nos estudos anteriormente referenciados, foi também identificada como barreira, o facto da família dos sujeitos não incentivar a prática de exercício físico e também ser sedentária. Também identificaram o excesso de peso e a idade avançada. Em alguns casos, o facto de o indivíduo ser o único progenitor, ou seja, ter uma família monoparental, também dificulta a prática de exercício. Por último foi também referido o dispêndio monetário (Ransdell et al., 2004).

Por sua vez, Dwyer, Allison, Goldenberg, Fein, Yoshida e Boutilier (2006) investigaram um grupo de 73 raparigas entre os 15 e os 16 anos de diversos grupos étnico-culturais residentes em Toronto, Canada. No final do estudo, os investigadores agruparam as barreiras descritas pelas participantes nas seguintes categorias: falta de tempo, devido aos trabalhos de casa, ao emprego em part-time e às responsabilidades familiares; envolvimento em actividades relacionadas com tecnologias, tais como ver televisão, falar ao telefone, navegar na Internet; atitudes negativas por parte dos professores, pais e colegas; preocupações pessoais e parentais com a sua segurança; poucos facilitadores, falta de transportes, mau tempo; não gostar de competição; e preocupações centradas no seu próprio corpo, tais como menstruação e feminilidade. Verificámos que as modalidades colectivas são "rotuladas" de "modalidades masculinas", enquanto a dança e a ginástica são "rotuladas" de "modalidades femininas" (Lee, Fredenburg, Belcher \& Cleveland, 1999).

Eyler (1998) realizou uma pesquisa sobre actividade física em mulheres pertencentes a minorias étnicas e encntraram barreiras extrínsecas aos sujeitos, tais como dispêndio monetário e questões associadas a sentimentos de segurança. Como barreiras intrínsecas encontrou a falta de tempo e a falta de motivação. Allison et al. (2005) com o intuito de explorar as razões de adolescentes do sexo masculino para participarem em actividade física moderada e elevada, avaliaram as barreiras percebidas para a prática de actividade física e as sugestões sobre o que pode ser feito para aumentar a participação em actividade física entre os adolescentes. Como amostra utilizaram 26 adolescentes de 3 escolas públicas de regiões diferentes de Toronto. As barreiras percebidas para a actividade física incluíram factores internos como a baixa prioridade para a actividade física, o envolvimento em actividades relacionadas com as tecnologias e falta de tempo. Como factores externos encontraram a influência dos pares e da família, e a inacessibilidade e o custo das instalações.

Rimmer, Riley, Wang, Rauworth e Jurkowski (2004) tiveram como propósito identificar barreiras e facilitadores associados à participação em actividades física e/ou exercício físico entre pessoas com incapacidades. Como barreiras foram identificadas as relacionadas com o meio ambiente, dispêndio monetário, dificuldades emocionais e psicológicas, ausência de ou falta de acesso a equipamentos, dificuldades no uso e interpretação de directrizes, códigos, regulamentos e formalidades leis, falta de informação, conhecimento profissional e de educação, percepções e atitudes de pessoas que não sofrem de incapacidades físicas, inclusive profissionais de saúde, e a indisponibilidade de recursos. O grau de participação em actividade física entre pessoas com incapacidades é afectado por um jogo multifactorial de barreiras e facilitadores que são únicos nesta população.

O facto é que todos podem beneficiar da actividade física: os pais e as crianças, os adolescentes, idosos, as pessoas que tentam controlar o seu peso, as pessoas com pressão alta, as pessoas com incapacidades físicas, incluindo artrites, pessoas que sofrem de stresse, inclusive pessoas que experienciam ansiedade e depressão (Centers for Disease Control and Prevention, 2008).

$\mathrm{Na}$ medida em que a Psicologia do Exercício é uma área do conhecimento que estuda, de uma forma geral, as relações entre a activi- 
dade física e o bem-estar e tem como principal objectivo compreender as razões que levam uns indivíduos a optar por estilos de vida activos e outros por estilos de vida mais sedentários, achámos de alguma relevância descrever quais as barreiras para a prática de exercício físico numa população adulta residente no interior norte de Portugal. Desta forma, a nossa questão de investigação é: "Quais são as barreiras para a prática de exercício físico em uma amostra de adultos?". Este estudo, através dos discursos dos sujeitos entrevistados, visa conhecer os conceitos emergentes e considerados como barreiras para a prática de exercício físico. Entendemos por barreiras para a prática de exercício físico algo que dificulte ou impeça os indivíduos de praticar. Estas barreiras podem ser intrínsecas ou extrínsecas aos indivíduos, sendo que as barreiras intrínsecas implicam um locus de controlo interno e portanto dão ao indivíduo a vantagem de só depender dele para a superação dessas barreiras percepcionadas. As barreiras extrínsecas implicam um locus de controlo externo e portanto não estão directamente dependentes da vontade do indivíduo para s superar (por exemplo, a falta de infra-estruturas). Tendo em conta o carácter multifactorial das barreiras para a prática de exercício físico, procurámos conhecer várias dimensões susceptíveis de dificultar a prática de exercício físico, contemplando a compreensão do Homem enquanto ser bio-psico-sócio-cultural.

\section{MÉTODOS}

O nosso estudo orienta-se pelo paradigma qualitativo e pela perspectiva émica e o modelo ideográfico visto que o que pretendemos aqui não é uma generalização, mas sim a compreensão do indivíduo enquanto entidade única, mas complexa. É um estudo de natureza transversal devido ao facto da recolha de dados ocorrer apenas num único momento. Convém também salientar que o nosso estudo tem um carácter exploratório, revestido de uma ampla e actual pesquisa bibliográfica.

\section{Amostra}

A amostra do nosso estudo é composta por 13 sujeitos, 7 do sexo feminino e 6 do sexo masculino, com idades compreendidas entre os 21 e 35 anos (a idade constituiu-se como único facto de inclusão para participar no estudo). Esta amostra foi recolhida no norte de Portugal. Divide-se em 6 praticantes de exercício físico e 7 não praticantes. Os indivíduos da nossa amostra que praticam exercício físico, ao nível profissional, são estudantes, professores de educação física e desporto, professores de natação, funcionários públicos e professores estagiários de educação física e desporto. Por sua vez, os não praticantes são estudantes, polícias e empregados de escritório. Para além disso, 3 dos participantes são casados, 9 são solteiros e 1 encontra-se em união de facto.

\section{Instrumentos}

Como instrumento usamos a entrevista centrada no problema. Esta entrevista faz parte das entrevistas semi-estruturadas. $O$ interesse por este tipo de entrevista deve-se principalmente à expectativa de os pontos de vista dos sujeitos serem mais facilmente expressos em situação de entrevista semi-aberta, do que numa entrevista estruturada ou num questionário (Flick, 2005). Por sua vez, a entrevista centrada no problema, foi sugerida por Witzel, na primeira metade dos anos 1980, e tem sido principalmente aplicada na Psicologia na Alemanha (Flick, 2005). Neste tipo de entrevista usa-se um guião de entrevista com questões específicas e estímulos narrativos permitindo, assim, recolher dados biográficos tendo por base um determinado problema. Os critérios nucleares a ter em conta aquando da realização de uma entrevista centrada no problema são: a centração no problema, ou seja, a orientação do investigador para um problema social relevante (neste caso o facto de os portugueses serem, na maioria, inactivos e quais as barreiras para a prática de exercício físico); a orientação para o objecto, isto é, os métodos são elaborados ou modificados tendo 
em conta o tema da investigação; finalmente, a orientação processual, tanto no processo de pesquisa, como no modo de entender o objecto da investigação (Flick, 2005). Na sua concepção enquanto entrevista qualitativa, a entrevista centrada no problema compreende um curto questionário precedente, o guião da entrevista, o registo gravado e o conteúdo posteriormente transcrito.

O guião da entrevista foi desenvolvido tendo por base as variáveis identificadas durante as leituras relativas à revisão bibliográfica levada a cabo. A literatura mais importante para a elaboração do guião foi a seguinte: um periódico de Lawton, Ahmad, Hanna, Douglas e Hallowell de 2005 chamado "I can't do any serious exercise": barriers to physical activity amongst people of Pakistani and Indian origin with Type 2 diabetes"; um periódico de Levins, Redenbach e Dyck de 2004 com o nome "Individual and Societal Influences on Participation in Physical Activity Following Spinal Cord Injury: A Qualitative Study"; um estudo do Center for Active Living de Alberta, Canadá, de 2004, intitulado "Depression as a Barrier to Older Adult Participation in Physical Activity"; um estudo de Amesty de 2003 intitulado "Barriers to physical activity in the Hispanic community"; recorremos também ao website do Center for Disease Control and Prevention onde podemos verificar as barreiras identificadas e muitas mais, e o questionário "Barriers to Being Active Quis, What keeps you from being more active?" desta mesma instituição. Procuramos que o nosso guião fosse o mais multidisciplinar possível abrangendo várias dimensões passíveis de dificultar a prática de exercício físico.

\section{Procedimentos}

Os três elementos do grupo, em conjunto, realizaram as entrevistas e distribuirão as tarefas de acordo com as funções assumidas individualmente. Enquanto um estava responsável por estabelecer o diálogo com o entrevistado, outro ocupava-se das condições de gravação e o último tirava apontamentos acerca das expressões do sujeito e acerca do contexto, procurando sempre que este fosse sempre de fácil controlo para o entrevistado. O controlo do "território" da entrevista coloca o entrevistado mais à vontade e permite-lhe também uma melhor gestão do tempo se a entrevista for longa (Guerra, 2006). Ainda de acordo com este autor, o facto de serem vários investigadores permite, também, um maior controlo sobre o guião. Portanto, procurámos indivíduos entre os 21 e os 35 anos, que foi a faixa etária que nos comprometemos a estudar. Para além disso, procuramos também o chamado "bom informador", ou seja, indivíduos que tivessem disponibilidade e disposição para nos ceder a entrevista e uma boa capacidade de verbalização. Inicialmente, todos os entrevistados forma informados sobre os objectivos da pesquisa, tentando explicar o que se entendia por barreiras para a prática de exercício físico, para que os sujeitos pudessem perceber o que esperávamos deles. Depois, pedíamos para assinarem um termo de consentimento que os informava acerca da duração prevista da entrevista, da sua gravação, do problema abordado, das condições de realização da entrevista e o anonimato e confidencialidade dos dados fornecidos.

Depois de instalados e iniciada a gravação, tentámos manter sempre um bom ambiente com o entrevistado, não tendo como preocupação seguir escrupulosamente o guião, mas colocando novas questões quando parecesse necessário e adequado, de modo a nos permitir seguir os princípios da não-directividade, especificidade, amplitude e profundidade/ atenção ao contexto pessoal. Também inquirimos os respondentes acerca de alguns dados demográficos, tais como: idade, sexo, estado civil e profissão. Em seguida, questionamos as pessoas acerca do significado do conceito "exercício físico", da sua prática de exercício físico e qual a intensidade e duração. O guião procurava conhecer as barreiras para a prática de exercício físico, inicialmente, em 10 dimensões; no entanto, tínhamos sempre em conta a 
possibilidade de surgir alguma dimensão que não tivéssemos incluído no guião. No final da entrevista lançávamos uma questão mais directiva perguntando aos sujeitos directamente quais são as barreiras que eles identificam.

Para analisar os dados obtidos utilizamos a codificação. Este método permite-nos categorizar o material e formular uma teoria enraizada. O principal objectivo da codificação é reduzir o material textual, parafraseando-o, resumindo-o ou categorizando-o. Este método foi elaborado por Glasser e Strauss e posteriormente desenvolvido por Glasser, quase uma década depois, e aperfeiçoado nos anos de 1990 por Strauss e Corbin (ver Flick, 2005). Entendemos por codificação as operações pelas quais os dados são divididos, conceptualizados e reagrupados de forma diferente. É o processo nuclear de construção das teorias a partir dos dados (Flick, 2005). Portanto, este é um processo que nos permite a obtenção de constructos /dimensões a partir das narrativas dos sujeitos.

\section{RESULTADOS E DISCUSSÃO}

Sendo o objectivo do nosso estudo conhecer as barreiras para a prática de exercício físico em uma população adulta, através dos discursos dos participantes obtivemos 7 constructos: 1- falta de tempo; 2 - Desinteresse/Aversão pelo exercício físico; 3- Incompetência; 4- Suporte familiar/pares; 5- Estereótipos/ Preconceitos sexuais; 6- Falta ou insuficiência de infra-estruturas/ Condições; 7- Carência de recursos económicos/monetários, e que passamos a descrever.

\section{Falta de tempo}

A "falta de tempo" foi uma das principais barreiras que identificámos. Os não-praticantes afirmaram não ter tempo para praticar exercício físico, declarando que o seu dia-a-dia é muito preenchido e que falta o tempo para incluir o exercício físico. No entanto, isto pode estar muito relacionado com as prioridades que os indivíduos definem. Em muitos casos o exer- cício físico fica para segundo plano.

"Para ir ao ginásio ou natação não tenho tempo ...é preciso despender algum tempo para fazer exercício físico. Não tenho muito tempo para o incluir."

"Durante o tempo de aulas é para mim impossivel praticar exercício físico num ginásio, ou melhor, num local específico para o fazer é mesmo impossível."

Para os praticantes de exercício físico, a falta de tempo não é uma barreira. Estes sujeitos defendem que a falta de tempo funciona como uma desculpa para a falta de vontade. Realçam a importância da motivação e independentemente do quão preenchido possa ser o seu dia com outras actividades, eles não dispensam o exercício físico enquanto actividade prioritária e essencial para se sentirem bem com eles próprios e sentirem-se mais produtivos.

"Basta querer, nem que seja à meia-noite! É preciso é haver vontade, que é o mais importante."

"Se uma pessoa quiser tem tempo. Por vezes temos de fazer sacrifícios, por exemplo levantar-se mais cedo. É tudo uma questão de força de vontade."

Noutros casos, os sujeitos praticantes afirmam ver o seu tempo disponível para a prática de exercício físico reduzido, mas não deixam de praticar, simplesmente reorganizam as suas actividades diárias de modo a poder incluir exercício físico.

“...o tempo que tenho é no final das aulas. O que significa que em vez de estar até à meia-noite a estudar vou estar até às duas da manhã ...é complicado mas com um bocado de esforço."

Assim, o trabalho e as tarefas domésticas tornam difícil a conciliação entre estas ocupações e o exercício físico mas, no entanto, não a tornam impossível. Contudo, os sujeitos não praticantes são conhecedores dos benefícios da prática de exercício físico, apesar de não o incluírem no seu dia-a-dia. Dwyer et al. (2006), 
Allison et al. (2005) e Ransdell et al. (2004) também identificaram como barreiras a falta de tempo muitas vezes devido ao trabalho e à conciliação do exercício físico com as restantes actividades diárias associado à ausência de vontade para praticar e às prioridades que os sujeitos definem (Allison et al., 2005).

A primeira dimensão, falta de tempo devido ao trabalho, implica claramente um locus de controlo externo ao sujeito. Um estudo de Cameron e Craig (2004) sugere que $74 \%$ das empresas canadianas não possuem políticas de trabalho que permitam aos funcionários trabalhar em casa, $21 \%$ adoptaram estas políticas, mas apenas de forma não oficial e só $4 \%$ têm oficialmente institucionalizado que os funcionários podem trabalhar em casa. Isto não fornece aos indivíduos flexibilidade laboral nem o necessário encorajamento para a prática de exercício físico. Ainda segundo o mesmo instituto, $46 \%$ dos locais de trabalho não têm políticas que enfatizem uma flexibilidade no horário laboral. Tendo em conta o facto de dois em cada cinco empregados considerarem a falta de tempo devido ao trabalho uma importante barreira para ser activo, a existência de alguma flexibilidade no seu trabalho poderia ser essencial para que estes indivíduos tivessem um estilo de vida mais activo fora do tradicional horário laboral (Cameron \& Craig, 2004). Verificámos também que os indivíduos do sexo masculino que têm uma carga horária laboral de, pelo menos, $48 \mathrm{~h}$ por semana são menos propensos para se envolverem em exercício físico semanalmente. Efeito semelhante verifica-se nas mulheres com uma carga horária laboral de 30h semanais (Popham \& Mitchell, 2006). Quando os indivíduos estão demasiado condicionados por factores externos tendem a sentir-se menos motivados intrinsecamente para se envolverem em actividade física de uma forma regular (Craike, 2004). Portanto, para estes indivíduos a prática de exercício físico é algo muito instável ao longo do tempo (ora têm tempo para praticar, ora não têm), depen- dendo de muitas influências externas. Nestes casos, a intervenção seria mais necessária junto das administrações empresariais do que junto dos indivíduos.

A segunda dimensão, falta de tempo devido à conciliação do exercício físico com as restantes actividades diárias associado à ausência de vontade para praticar e às prioridades que os sujeitos definem, implica um locus de controlo interno ao sujeito. Portanto, enquanto a flexibilidade laboral é algo que depende de factores externos, o tempo de lazer não. A organização das actividades a que o indivíduo se dedica para além do tempo laboral e a inclusão do exercício físico nessas actividades, depende acima de tudo das prioridades definidas. Vemos que, as pessoas que preferem participar em actividade física durante o seu tempo de lazer tendem a dar-lhe muita prioridade e, consequentemente, encontram sempre tempo para se envolverem neste tipo de actividades (Craike, 2004). No mesmo estudo Craike verificou também que o facto de os sujeitos encontrarem tempo para se envolverem em actividade física estava associado a um aumento da regularidade na participação neste tipo de actividades. Como sabemos, as pessoas tendem a dar prioridade àquilo que gostam de fazer, ou seja, àquilo em que se divertem. Com isto, vemos que o facto das pessoas se conseguirem divertir, ou não, ao praticar exercício físico, vai influenciar a sua preferência por este tipo de actividades enquanto actividade de lazer. Uma pessoa que se diverte é uma pessoa motivada de forma intrínseca. Portanto, esta, a motivação intrínseca, é uma variável de extrema importância para a inclusão de exercício físico no tempo de lazer. Esta variável mostra uma influência positiva na participação regular em actividade física, isto porque, ao mesmo tempo que ela aumenta a preferência por este tipo de actividades aumenta também o nível de satisfação e capacidade para se divertir aquando do envolvimento neste tipo de actividades (Craike, 2004). Numa relação que é bidireccional, existe uma 
influência mútua entre o divertimento e a motivação intrínseca. Quanto mais o indivíduo se sente motivado intrinsecamente maior a satisfação e o prazer que obtém ao praticar estas actividades, e à medida que aumenta o prazer e a satisfação, a motivação intrínseca tende a acompanhar o sentido desta evolução (porque, afinal, a motivação intrínseca significa retirar prazer daquilo que se faz). Portanto, um indivíduo intrinsecamente motivado para o envolvimento em actividade físico vai atribuir a prioridade necessária a esta actividade no seu tempo de lazer. Em suma, vemos que as preferências e as prioridades que os sujeitos definem têm uma grande importância na sua avaliação da disponibilidade para o envolvimento em actividade física e, consequentemente, na participação regular neste tipo de actividades durante o horário extra laboral (Craike, 2004).

Isto também é evidente no estudo publicado por Kimm et al. (2006), onde a disponibilidade extra laboral dos participantes sedentários é semelhante à dos indivíduos activos, mas, no entanto, os primeiros afirmam não ter tempo. Podemos considerar também que o facto de praticarem exercício físico há muito tempo e este fazer parte do seu estilo de vida activo faz com que os praticantes não considerem a falta de tempo como barreira. Tal efeito foi verificado por Ransdell et al. (2004) quando referiu que as participantes adultas depois de praticarem exercício físico durante 12 semanas, evidenciaram muito menos barreiras para a sua prática.

No seguimento das entrevistas parece-nos que transparece a ideia que a melhor forma de interpretar a noção de "falta de tempo" na medida em que tal afirmação representa mais uma "falta de habilidade para a gestão do tempo" de que dispõem, uma vez que as rotinas diárias dos praticantes e não-praticantes não deixa transparecer essa declarada falta de tempo num dos grupos. Vemos, graças aos sujeitos praticantes, que é necessário definir o exercício físico também como uma prioridade na definição das tarefas a priorizar no dia-a-dia. Esta falta de habilidade associada à falta de vontade constituem-se uma dos maiores impedimentos.

\section{Desinteresse/Aversão pelo exercício físico}

Quando os sujeitos descrevem o seu desinteresse pelo exercício físico a análise aos conteúdos da narrativa, encontramos mais substância para expressarem um eventual receio do julgamento por parte de outros. Aqui os respondentes evidenciam receio pela atitude dos outros relativamente ao seu desempenho, frequentemente relacionado com o embaraço aquando da prática. Estes estados motivacionais, como já referido anteriormente, vão aumentar a apreensão e o medo de uma avaliação corporal negativa e, consequentemente vai despoletar um desejo de desistência e evitamento (Alves et al., 2008).

"Eu deixei de fazer exercício físico porque sou uma patareca com bolas. Tenho medo das bolas e também a sensação que as outras pessoas pudessem estar a gozar comigo, também me fazia ter receio."

Constatámos, também, que existe um certo receio com a hipótese de se magoarem. Os casos relativamente a actuais de jogadores profissionais e mesmo amadores que sofreram ataques cardíacos que os levaram à morte, deixa nos sujeitos o receito que lhes pode acontecer o mesmo e consequentemente verifica-se um afastamento da prática desportiva. Ou então, o facto de percepcionarem alguns exercícios como mais capazes de afectar a sua integridade física.

"Desde que vi os jogadores a morrer em campo fico com receio. Então, é por isso que eu não vou. Imagine que me dá uma paragem cardíaca!? É melhor não! .... Penso que posso ficar sem ventilação e não está lá ninguém para me ajudar. E depois? Como é que eu faço?"

"Na ginástica tenho um certo receio. Mas é assim, 
no trampolim tenho muito receio, nomeadamente o salto mortal porque já vi pessoas que se magoaram muito."

A ausência de motivação para a prática de exercício físico está frequentemente associada ao sedentarismo. $\mathrm{O}$ facto de os sujeitos encararem o exercício físico como aborrecido, leva-os a arranjar desculpas minimamente plausíveis (pelo menos para eles) para não praticarem exercício. Isto é, aquilo a que eles frequentemente se referiram como "sem apetite". A preferência, que é quase uma tentação, pelas actividades mais sedentárias, geralmente relacionadas com as novas tecnologias, está muitas vezes associada à preguiça. Kolt et al. (2006) obteve resultados semelhantes ao verificar que os participantes não mostravam níveis elevados de motivação para a prática de exercício físico, tal como os resultados obtidos por Eyler (1998). O envolvimento em actividades relacionadas com as novas tecnologias foi também referido por Dwyer et al. (2006) e por Allison et al. (2005) entre os mais sedentários. Estes estudos verificaram que os sujeitos também afirmavam que a prática desportiva é "aborrecida" e "chata". Todas estas razões levam a um relativo, ou completo, afastamento da prática de exercício.

"Eu arranjo desculpas, ou porque está a chover, ou porque está calor demais ou porque está vento...é mesmo porque não gosto, canso-me! Não sei como é que há pessoas que conseguem dizer depois de praticar exercício 'ai estou tão aliviada'...no $12^{\circ}$ ano meti sempre atestado para não fazer educação física.... Eu tempo tenho, só que arranjo desculpas para não ter. Mas se eu quisesse até tinha para dar umas caminhadas, mas não quero, não estou para aí virada.... Eu comprei uma bicicleta estática mas está cheia de ferrugem...até fiz uma promessa de ir a pé a Santiago. Todos os anos que chega Janeiro penso 'agora tenho de começar a caminhar para aguentar a ir a pé', mas não dá, não tenho motivação nenhuma."

\section{Incompetência}

Existem muitos complexos associados à idade. Os indivíduos percepcionam o avançar do tempo como algo condicionante, mas qualquer indivíduo em qualquer idade pode praticar exercício físico e obter benefícios que daí advêm (Centers for Disease Control and Prevention, 2008). Todavia, é necessária uma adaptação da prescrição do exercício à população alvo. Frequentemente, os indivíduos fazem o contraste entre o seu estado actual e aquilo que eram capazes de fazer numa etapa anterior da sua vida.

"A idade começa a pesar um bocado. Sinto que já não sou tão rápido. Já não tenho 20 anos e a recuperação já não é tão rápida, o metabolismo é mais lento."

"Em certas idades, por exemplo, uma pessoa de 60 anos não pode fazer à mesma velocidade que eu faço."

"Á medida que aumenta a idade há mais possibilidades de se ter lesões."

No estudo de Wilcox et al. (2005) estes argumentos são evidentes. As participantes referiram correr muitos riscos aquando da prática de exercício físico, afirmando estarem "muito velhas" para se envolverem nesta actividade. Estes resultados são claros quanto às percepções que os indivíduos têm em relação à idade associada à prática de exercício. Estas percepções estão muitas vezes associadas ao nível de instrução e informação que os indivíduos possuem, tal como referido por Amesty (2003).

A prática de exercício está também condicionada pelo facto de os sujeitos considerarem não possuir as habilidades necessárias para exercer algum tipo de exercício. Subvalorizam as suas capacidades em determinadas actividades.

"Há tipos de exercícios físicos que não tenho habilidade nenhuma para praticar."

"Se me pusessem a praticar umas acrobacias quaisquer não era capaz." 


\section{Suporte familiar/pares}

A família e os pares também parecem ter um papel importante no nível de participação dos indivíduos em programas de exercício físico. Tal como Amesty (2003) sugere, os indivíduos com um fraco suporte social têm tendência para serem mais inactivos do que aqueles que referem ter boas relações sociais e suporte social, especialmente os que dizem beneficiar do suporte familiar e dos amigos. Para além disso, a família e os amigos têm grande poder no que se refere à motivação inicial para o envolvimento em exercício físico (Amesty, 2003). Vemos que a influência negativa por parte da família e dos pares está associada a hábitos sedentários e a estilos de vida não saudáveis. Muitos dos hábitos sociais portugueses, actualmente não contemplam actividades que correspondam a um estilo de vida activo.

"A mulher está em casa, também quero a companhia dela, até posso aproveitar para navegar na Internet, ver televisão ..."

"Se eu desde pequena visse a minha mãe a praticar exercício se calhar até praticava, mas eu nunca os vi a fazer nada! ... são todos sedentários! Ninguém faz nada, é tudo pior que eu! A minha mãe diz que só faz ginástica de sofá e eu herdei tudo isso .... Moram no $1^{\circ}$ andar e vão de elevador."

"Muitas vezes, na época do secundário, os meus amigos iam para o café, ou ver um filme e eu tinha treinos àquela hora e bastantes vezes não ia aos treinos e ficava com eles."

Também Allison et al. (2005) obtiveram os resultados semelhantes numa amostra de adolescentes que afirmaram que os hábitos pouco activos dos familiares e amigos tinham influência sobre a sua participação em exercício físico.

\section{Estereótipos/Preconceitos sexuais}

Ainda se verifica, actualmente, os "rótulos" que definem uma prática desportiva como "masculina" ou "feminina". Frequentemente, os desportos colectivos são "rotulados" de "modalidades masculinas" e actividades como dança ou ginástica ficam com o "rótulo" de "modalidade feminina" (Lee et al., 1999). Isto é condicionador, principalmente quando as mulheres afirmam que frequentemente os homens não as querem incluir na prática de exercício físico, nomeadamente no futebol. Isto leva a que, mesmo que às vezes se sintam motivados, os indivíduos vejam as suas oportunidades, para participar em exercício físico, reduzidas e assim diminuem os seus níveis motivacionais intrínsecos.

“...os homens são muito mais preconceituosos do que as mulheres. No futebol eles se calhar nem aceitam jogar com mulheres."

"Futebol feminino não tem lugar em Portugal. Seja futebol feminino sejam outras modalidades de desporto feminino. Não se fala! No entanto temos boas desportistas, mas ainda há bastante preconceito."

Estes estereótipos eram notórios no discurso dos sujeitos, visto que quando se falava em preconceitos sexuais eles rapidamente diferenciavam "modalidades masculinas" de "modalidades femininas". Vimos, pelos discursos, que à mulher cabem as tarefas relacionadas com a lida de casa. Isto está claramente relacionado com as expectativas sociais e culturais. Para além do trabalho têm de realizar as tarefas domésticas porque, assim se considera, é algo que lhes compete a elas e, portanto, elas praticam exercício físico se, depois de terminadas as "obrigações" domésticas/familiares, tiverem tempo.

"Se formos a fazer uma análise geral, hoje em dia as mulheres também trabalham, mas como antigamente, também costumavam ser elas a fazer os trabalhos de casa.... E depois do emprego é vir para casa, fazem os trabalhos e, se metermos o exercício no meio, onde é que ela vai ter tempo de fazer o jantar? Quer dizer, só se for à hora de almoço! Mas depois não almoça e depois cria ali um desequilíbrio." 
"Uma mulher quando é solteira é uma coisa, quando é casada é outra. Tem que fazer todas as lidas de casa e o marido não faz nada, 'tá no sofá, por isso (ele é que) pode muito bem ir praticar exercício."

\section{Falta ou insuficiência de infra-estruturas/ Condições}

Esta foi apontada como outra das principais barreiras. Os indivíduos queixam-se da falta de apoio das entidades competentes (como as câmaras municipais) que não apostam na manutenção das infra-estruturas e que investem para possibilitar uma oferta diversificada de modalidades. Em termos de instalações, estes organismos possuem ginásios e algumas piscinas, não havendo um incentivo para outras modalidades ao ar livre (que não seja futebol). Apesar de se conseguir praticar com as condições disponíveis, os sujeitos consideram que em muitos casos seriam necessárias infra-estruturas remodeladas e adaptadas às necessidades/preferências dos indivíduos.

"Infra-estruturas há muito poucas. Uma pessoa que queira fazer alguma coisa quando está a chover não tem sítio."

"Nas 'horas de ponta' das piscinas, elas estão muito cheias.... Deveria haver locais mais propícios."

"Podia estar melhor preparado para as pessoas poderem estar à vontade. Neste momento acho que não há locais suficientes para se poder praticar, principalmente à noite. Aqui, "a cidade", podia ter mais condições. Em caminhadas as pessoas andam e os carros praticamente ao lado. Fazer o circuito "da cidade" é bom, mas a gente está a respirar o cheiro do escape dos carros... aqueles gases."

Em muitos casos verifica-se uma insatisfação com o facto de não haver possibilidade de optar pela modalidade que mais se gosta ou gostaria de praticar, tal como verificado por Allison et al. (2005). Haveria probabilidade de termos indivíduos mais activos, caso estes tivessem condições de praticar o desporto que lhes dá prazer, o que levaria a um consequente envolvimento nessas actividades de modo a promover a sua saúde.

"Por exemplo, eu gosto de jogar ténis mas aqui não tenho condições. Acho que há um campo à beira do aeródromo, mas é muito longe."

\section{Carência de recursos económicos/monetários}

Os participantes referiram também que os preços da inscrição para a prática de algumas modalidades são muito elevados. Realçando que não é qualquer pessoa que tem possibilidades de suportar um agregado familiar e manter-se inscrito num ginásio. Allison et al. (2005) também identificaram como barreiras a inacessibilidade e custo da utilização das instalações, tal como nós. Eyler (1998) verificou que uma das principais barreiras referidas pelos participantes era o dispêndio monetário derivado da participação em exercício físico em instituições. Portanto, existe falta de equipamentos próximo da área residencial e em alguns casos agravado pela falta de transportes (Wilcox et al., 2005). Sem estas condições, não é muito fácil para as pessoas participarem em programas de exercício físico de um modo relativamente "cómodo para a sua carteira", embora certas actividades físicas, como a caminhada ou corrida, por exemplo, não exijam grande dispêndio monetário, mas as localidades onde o possam fazer de forma satisfatória parece não estão disponíveis. Os participantes destacam o impacto financeiro que a utilização de algumas infra-estruturas acarretam para o orçamento familiar, em especial quando a prática implica a compra de determinados equipamentos. Portanto, uma família que não esteja economicamente preparada para suportar os gastos associados à participação em ginásios, ou natação, terá de optar por outras formas de se "mexer", como caminhar, mas nem sempre em boas condições para tal.

"Hoje em dia está complicado! Hoje em dia está muito complicado! Eu vejo por mim, quem tiver uma casa, quem tiver uma família é complicado! Basta ter 
um crédito à habitação para uma pessoa não poder usufruir de muitas coisas, quanto mais de um ginásio! Acho que é o factor essencial, o dinheiro é o factor essencial. E acredito que muitas pessoas não frequentam o ginásio por esse motivo.... Ainda há pouco tempo estive a pensar comprar uma bicicleta estática para praticar desporto, mas anda por volta dos 200, 300 euros. Hoje em dia, 200, 300 euros fazem muita diferença no orçamento familiar."

"Se calhar eu até queria (ir para o ginásio), mas depois vem o outro lado, o lado monetário. Ou seja, em termos económicos fica um pouco dispendioso ir para o ginásio."

\section{CONCLUSÃO}

A falta de tempo parece ser uma barreira relevante para a prática de exercício físico. No entanto, consideramos este aspecto nós que a razão "falta habilidade para gestão do tempo" é mais adequada/inclusiva devido à discrepância de crenças e atitudes entre praticantes e não-praticantes. Enquanto os não-praticantes afirmam que o seu dia é demasiado preenchido para poder praticar exercício físico, os praticantes consideram isso irrelevante, sendo que o que realmente importa é ter vontade para praticar exercício e defini-lo como uma prioridade.

Em muitos casos, o desinteresse pelo exercício físico foi uma barreira, visto que os indivíduos consideram chato praticar exercício o que os leva a não ter vontade de praticar. Em outros casos os sujeitos revelam algum receio do julgamento dos outros que os leva a sentir embaraço enquanto praticam exercício. A idade surge como factor condicionador, em alguns casos, assim como a falta de habilidades, o que tendo em consideração a faixa etária estudada representa uma desculpa pouco coerente.

Os grupos sociais mais próximos do indivíduo (família e pares) também têm um papel determinante na sua participação em exercício físico, visto que os seus hábitos sedentários (dos indivíduos entrevistados), em muitos casos, são o espelho dos hábitos familiares e dos pares. Os homens e as mulheres, principalmente as mulheres, vêem a sua participação em determinadas modalidades condicionada devido aos estereótipos existentes.

Por sua vez, as infra-estruturas deficitárias ou inexistentes, associadas aos preços demasiado elevados e à condição económica da sociedade em geral, dificultam a participação em modalidades, em que é necessário algum tipo específico de equipamento.

Tememos que algumas questões não tenham sido formuladas da forma adequada. Esperamos que em estudos posteriores em que o guião, eventualmente, seja utilizado, os investigadores tenham isso em conta e procedam a eventuais e tidas como necessárias algumas reformulações.

Visto que a nossa amostra foi recolhida num concelho do interior norte de Portugal, seria interessante que um estudo futuro de natureza quer qualitativa quer quantitativa procurasse confirmar as hipóteses que aqui se levantam numa população adulta mais vasta, de forma a podermos conhecer os seus problemas e as suas necessidades, com o intuito de agir de forma a melhorar a sua qualidade de vida.

\section{Agradecimentos:}

Nada declarado.

\section{Conflito de Interesses:}

Nada declarado.

Financiamento:

Nada declarado.

\section{REFERÊNCIAS}

Alberta Center for Active Living (2004). Depression as a barrier to older adult participation in physical activity. Research Update, 11(1). Acedido a partir de http:// www.centre 4 activeliving.ca/publications/ research_update/ActiveLivingMarch.htm Allison, K., Dwyer, J., Goldenberg, E., 
Fein, A., Yoshida, K., \& Boutilier, M. (2005). Male adolescents' reasons for participating in physical activity, barriers to participation, and suggestions for increasing participation. Adolescence, 40(157), 155-170.

Alves, D., Cunha, F., \& Leirós, V. (2008). Execício físico, ansiedade social e ansiedade física social. Estudos de Psicologia do Exercício e Saúde, 1, 15-34. Vila Real: CEDAFES-UTAD.

Amesty, S. C. (2003). Barriers to physical activity in the Hispanic community. Journal of Public Health Policy, 24(1), 41-58. doi: $10.2307 / 3343176$

Cameron, C., \& Craig, C. (2004). Increasing physical activity: Building active workplaces. Ottawa, ON: Canadian Fitness and Lifestyle Research Institute.

Carmo, I. (2001). Obesidade: A epidemia global. Revista da Faculdade de Medicina de Lisboa, 6(III), 39-46.

Caspersen, C., Powell, K., \& Christenson, G. (1985). Physical activity, exercise, and physical fitness: Definitions and distinctions for health-related research. Public Health Reports, 100(2), 126-131.

Centers for Disease Control and Prevention (2008). Physical activity and health, everyone can benefit from physical activity. Acedido a partir de http://www.cdc. gov/nccdphp/dnpa/ physical/everyone/ health/index.htm

Craike, M. (2004). An exploratory study of the social psychological determinants of regular participation in leisure-time physical activity. Tese de Doutoramento, Brisbane: Griffith University.

Dwyer, J., Allison, K., Goldenberg, E., Fein, A., Yoshida, K., \& Boutilier, M. (2006). Adolescent girls' perceived barriers to participation in physical activity. Adolescence, 41 (161), 75-89.

Eurobarometer (2004). The citizens of the European Union and sport. TNS
Opinion \& Social, 213. Brussels: European Commission.

Eurobarometro (2018, 21 March). Sports and physical activity. 472. Brussels: European Commission.

Eyler, A. (1998). Physical activity and minority women: A qualitative study. Health Education \& Behavior, 25(5), 640-652. doi: $10.1177 / 109019819802500510$

Flick, U. (2005). Métodos qualitativos na investigação científica ( $1^{\circ}$ edição). Lisboa: Monitor - Projectos e Edições, Lda.

Guerra, I. (2006). Pesquisa qualitativa e análise de conteúdo - sentidos e formas de uso ( $1^{\circ}$ edição). Estoril: Principia Editora, Lda.

Kimm, S., Glynn, N., McMahon, R., Voorhees, C., Striegel-Moore, R., \& Daniels, S. (2006). Self - perceived barriers to activity participation among sedentary adolescent girls. Medicine $\mathcal{E}$ Science in Sports $\mathcal{E}$ Exercise, 38(3), 534-540. doi: 10.1249/01. mss.0000189316.71784.dc.

Kolt, G., Paterson, J., \& Cheung, V. (2006). Barriers to physical activity participation in older Tongan adults living in New Zealand. Australasian Journal on Ageing, 25(3), 119-125. doi: 10.1111/j.17416612.2006.00157.x

Lawton, J., Ahmad, N., Hanna, L., Douglas, M., \& Hallowell, N. (2006). 'I can't do any serious exercise': Barriers to physical activity amongst people of Pakistani and Indian origin with Type 2 diabetes. Health Education Research, 21(1), 43-54. doi: 10.1093/her/cyh042

Lee, A., Fredenberg, K., Belcher, D., \& Clveland, N. (1999). Gender differences in children's conceptions of competence and motivation in physical activity. Sport, Education and Society, 4(2), 161-174. doi: 10.1080/1357332990040204

Levins, S., Redenbach, D., \& Dyck, I. (2004). Individual and societal influences on participation in physical activity following spinal cord injury: A qualitative 
study. Physical Therapy, 84(6), 496-509. doi:10.1093/ptj/84.6.496

Norton, P., Burns, J., Hope, D., \& Bauer, B. (2000). Generalization of social anxiety to sporting and athletic situations: Gender, sports involvement and parental pressure. Depression and Anxiety, 12, 193-202. doi: 4(2000) 12:4<193::AID-DA2>3.0.CO;2-X

Pereira, J. \& Vasconcelos-Raposo, J. (1997). As motivações e a prática desportiva: Análise descritiva, factorial e comparativa dos motivos e factores motivacionais para a participação e não participação desportiva de jovens do concelho de Baião. Trabalho de não publicado. FCDEF, Universidade do Porto.

Popham, F., \& Mitchell, R. (2006). Leisure time exercise and personal circumstances in the working age population: Longitudinal analysis of the British household pane survey. Journal of Epidemiology and Community Health, 60, 270-274. doi: 10.1136/jech.2005.041194
Ransdell, L., Detling, N., Hildebrand, K., Lau, P., Moyer-Mileur, L., \& Shultz, B. (2004). Can physical activity interventions change perceived exercise benefits and barriers? American Journal of Health Studies, 19(4), 195-205.

Rimmer, J., Riley, B., Wang, E., Rauworth, A., \& Jurkowski, J. (2004). Physical activity participation among persons with disabilities: Barriers and facilitators. American Journal of Preventive Medicine, 26(5), 419-425. doi: 10.1016/j. amepre.2004.02.002

Wilcox, S., Oberrecht, L., Bopp, M., Kammermann, S., \& McElmurray, C. (2005). A qualitative study of exercise in older African American and white women in rural South Carolina: Perceptions, barriers, and motivations. Journal of Women \& Aging, 17(12), 37-53. doi: 10.1300/ J074v17n01_04 